\title{
Effect of Gamma Radiation on the Characterization of HDPE / Nanoclay
} Composites.

\author{
Elham M. Hegazi ${ }^{1}$, Eltohamy R. Elsharkawy ${ }^{1}$, A. A. Abd El-megeed ${ }^{2}$ \\ ${ }^{1}$ QC \& QA Department, Nuclear \& Radiological Regulatory Authority, Cairo, Egypt \\ ${ }^{2}$ Department of Polymers, National Institute for Standards, Cairo, Egypt
}

\section{Abstract}

Polymer nanocomposites consist of a polymeric substances and a nanoscale reinforcing materials. These materials show substantial improvements in mechanical properties, gas barrier properties, thermal stability, chemical resistance, dimensional stability and fire retardancy over the base polymer. The reinforcing effect of nano-clay on high density polyethylene (HDPE) and the effect of gamma radiation on the properties of HDPE with different ratios of nano-clay have been studied. The nano-clay are added to HDPE of 0\%, $3.0 \%, 5.0 \%, 7.0 \%$ and $10.0 \%$ by weight. After the nano composites are exposed to different doses of gamma radiation, the phase composition microstructure and mechanical properties of composites are investigated using tensile test, hardness and scanning electron microscope (SEM) techniques. Results show that the mechanical properties of nano-composites are improved due to addition of nano-clay. It is found that the optimum $3 \mathrm{wt} \%$ nano-clay addition. The microstructural analysis results indicate that the nano-clay behaves not only as a filler to improve the microstructure, but also as an activator to facilitate the polymer reaction. The mechanical properties were investigated as a function of irradiation dose and nano-clay content. Gamma irradiation led to a significant improvement in the properties for all composites up to $100 \mathrm{KGy}$.

Key words: High density polyethylene (HDPE), nano-clay, Gamma irradiation, mechanical properties, SEM.

Corresponding Author: Elham M. Hegazi (hegazi_4@yahoo.com)

\section{Introduction}

Polymer nanocomposites have existed for decades, as carbon black, pyrogenic silica and diatomite were used as additives in polymers. Polymer-clay nanocomposites are emerging as a class of advanced engineering materials. Several key properties, such as strength and 
permeation, can be improved by adding a small amount of clay into the polymeric matrix [1,

2]. The properties of polymer-clay nanocomposites depend on the degree of clay dispersion or on the extent of delamination of the individual clay layers in the polymeric matrix [3]. The clay layer is hydrophilic in nature and can be converted to organoclay to promote the wetting of the polymer molecule onto the clay surface $[4,5]$. The important advantages of using polymeric nanocomposites over conventional materials are processing ease, manufacturing versatility and low over-head production cost [6].

Nano composites are particle-filled polymers for which at least one dimension of the dispersed particles is in the nanometer range which have superior physical properties such as thermal, mechanical and barrier properties or some new properties comparing to the original polymer/filler composites [7].

The use of gamma radiation for the modification of polymers is well established and is used in many industrial processes to improve the thermal stability and mechanical properties. This process is clean, requires less energy, permits greater processing speed and operates at ambient temperature [8]. The mechanical properties of nanocomposites were studied before and after gamma irradiation. The morphological properties were examined by scanning electron microscopy (SEM).

\section{Experimental procedure}

\subsection{Materials}

High-density polyethylene (HDPE) with melt flow index 27 and was obtained from Viba Laborchemie, APOLDA, Germany. A sterically Amine antioxidant 6PPD was selected for this study. Modified nanoclay (Montmorillonite clay, Nanomer 1.34MN, SIGMAALDRICH, Co., USA). Maleic anhydride (Chemtura Polybond_ 3009) was added as a compatibilizer to improve the dispersion of nanoclay in the polymer matrix.

\subsection{Composites preparation}

All HDPE composites have been prepared by melt blending method using New plast twin screw extruder (India) at $155{ }^{\circ} \mathrm{C}$. The twin screw speed is $70-80 \mathrm{rpm}$ for about $15 \mathrm{~min}$.

\subsection{Mechanical Properties}

The tensile strength and elongation at break are measured by using a Zwick (Germany) Tensile Testing Machine (Model Z010) using five dumb-bell tensile specimens being shaped according to (ASTM D-412, 1998). The hardness test is measured by a Zwick (Germany) Hardness Tester Machine (Model 3150) according to (ASTM D-2240, 1997). 


\subsection{Gamma Irradiation}

The gamma irradiation process was carried out in ${ }^{60} \mathrm{Co}$ source of gamma facility represented at the National Center for Radiation Research and Technology (NCRRT) with rate 6.5 $\mathrm{KGy} / \mathrm{hr}$. The HDPE samples were irradiated to the required gamma doses $(0,50,100,200$ and 500) KGy.

The surface of HDPE at (Zero and 0.6 MGy) was studies with JEOL. JSM-5600 LV Scanning Electron Microscope, (Japan). Samples are cut and are sputter-coated with gold using a microscope sputter coater, viewed through the microscope at National Center for Radiation Research and Technology, Cairo, Egypt.

\section{Result and Discussion}

\subsection{Morphological Characterization}

Figures 4 (a, b, c and d) illustrate the SEM micrographs of HDPE / nanoclay composites blends as well as $3 \mathrm{wt} \%$ of nanoclay with exposed to different irradiation doses, 0,100,200and $500 \mathrm{KGy}$ as respectively. The trend of the mechanical properties is well explained by observing the SEM micrographs. In figure 4.b we it is seen that there is proper dispersion of the matrix and this is reason for maximum enhancement of mechanical properties at $3 \mathrm{wt} \%$ nano-clay containing composites. It may be observed that the structure improvement and mechanical properties for all samples $3 \mathrm{wt} \%$ nanoclay increase with increasing the irradiation dose up to $100 \mathrm{kGy}$. At higher doses beyond $100 \mathrm{KGy}$, the properties start to decrease with increasing irradiation dose up to $200 \mathrm{KGy}$ (fig 4c) and $500 \mathrm{KGy}$ (fig 4d). This increase is affiliated with formation of a higher number of crosslinks leading to better interaction between the modified clay and the polymer matrix [9].

\subsection{Mechanical Properties}

Figure 2 show the tensile strength (TS) of HDPE /nanoclay. Nanoclay were varied from 0 to 10 weight $\%$ of blend. The mechanical properties enhancement is found up to a nanoclay level of $3 \%$ and there after a slight decrease is found. At $3 \%$ nanoclay effective interaction of the filler with matrix occurred. The composites of HDPE with varying compositions nanoclay layers acts as stress transfer agents and resists breakage while bending. This gives better flexural strength for nanocomposites. There will be considerable improvement in these properties if the bonding between filler and matrix is strong. The decrease in strength after 
$3 \%$ nanoclay composition may be due to poor dispersion of clay particles by the agglomeration within the polymer matrix [10].

It can be observed that the TS is increased with the increase in radiation dose up to $100 \mathrm{kGy}$ and then decreased. The increase of TS due to gamma irradiation indicates the occurrence of crosslinking, whereas the decrease beyond the dose of $100 \mathrm{kGy}$ indicate the occurrence of oxidative degradation. From TS data, it is clear that TS increase gradually with increasing the content of nanoclay. This increase of tensile strength may be attributed not only to the higher surface area of the modified clay that will be in contact with polymer matrix macro molecules causing a good dispersion of clay in the polymer matrix but also due to the strong interaction between the modified clay and the matrix[11]. Accordingly, and as a result of irradiation in the presence of modified clay filler, the functional groups of intercalating agent may find additional sites for cross-links.
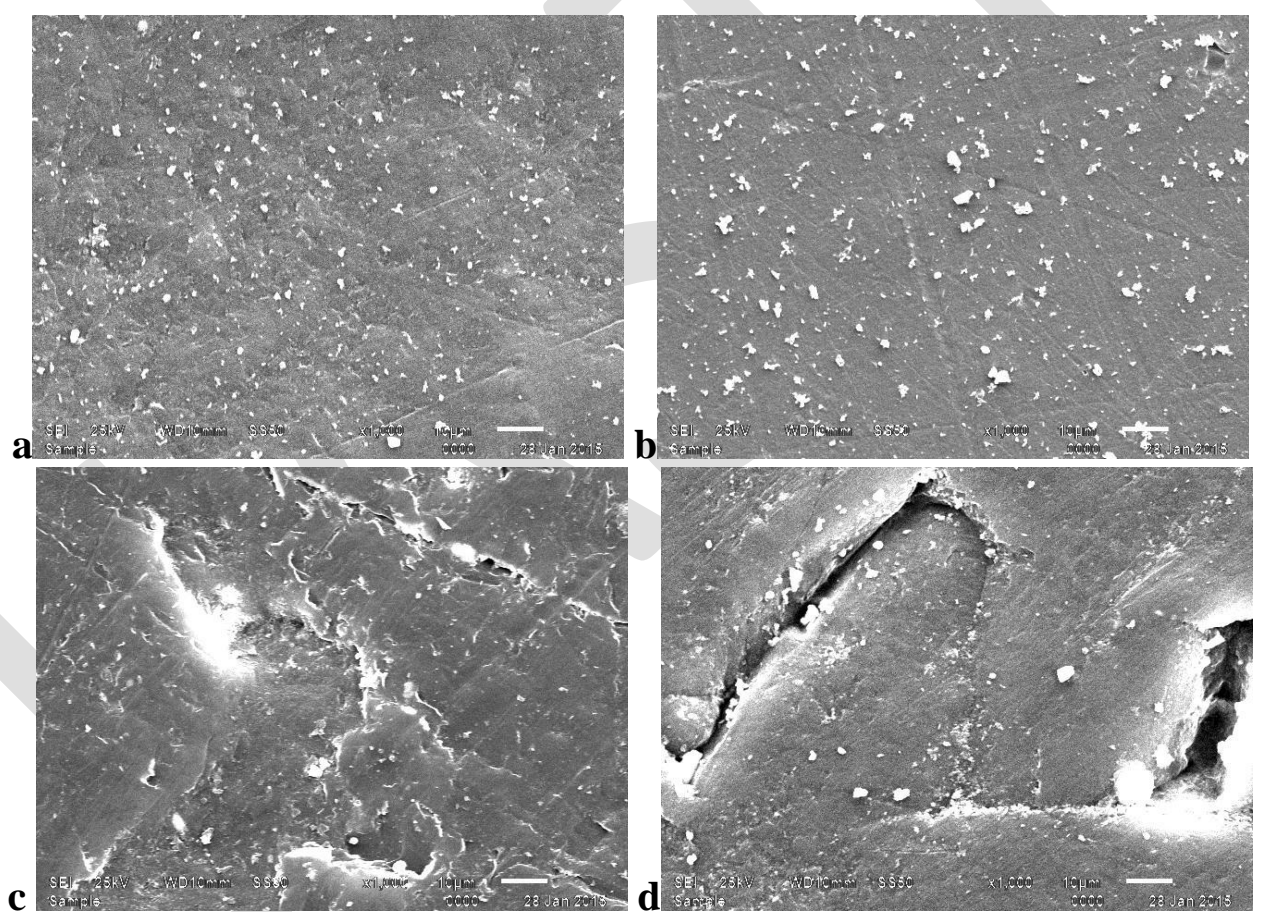

Figure 1: illustrates the HDPE filled with $3 \mathrm{wt} \%$ of nanoclay contents as a function of irradiation doses, a. 0KGy, b.100 KGy, c.200 KGy, and d.500 KGy.

Fig. 3 shows the effect of gamma irradiation on the elongation of composite HDPE /nanoclay samples. As the dose of irradiation increases, more cross-linking is induced in the sample, which prevents the structural reorganization during drawing and brings about a decrease in internal chain mobility and hence elongation [12]. Also, at high irradiation doses, the degradation reaction (i.e. cracks initiation) is another factor that contributes to much lower 
elongation values. As the matter or fact, as the data in Fig. 3 indicate, the role played by nano-clay in this respect may be considered the main parameter when the content of nano clay increase in the composite.

The hardness property is related to the capacity of prepared composites to resist mechanical penetration of a foreign body, namely a loaded indenter. The data are presented, therefore, in terms of the (A shore) hardness index. Figure 4 shows the effect of gamma irradiation dose on the hardness for the HDPE filled with different contents of nano-clay. It can be seen that the hardness increases moderately with increasing irradiation dose up to $100 \mathrm{kGy}$. Moreover, the hardness values increase again moderately with the increase of nano-clay content with respect to unloaded samples. The high hardness values due to addition of nanoclay may be due to the silicate nature of the nano-clay. Such silicate nature would be expected to resist mechanical penetration during measurements of the hardness functions. The relative slight increase in hardness value with irradiation in general may be affiliated with increase of radiation induced crosslinking [13].

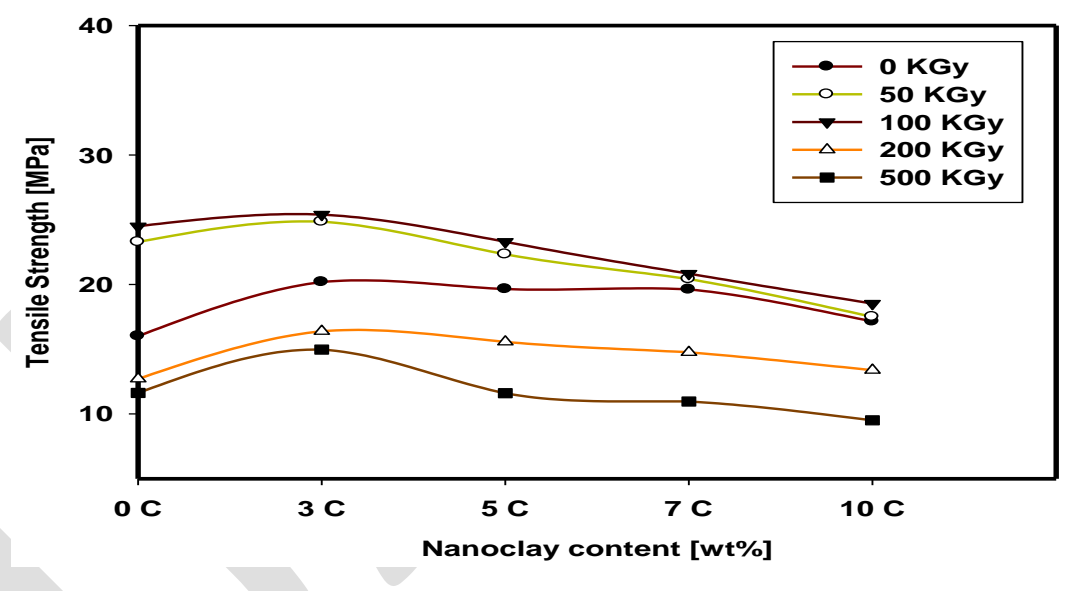

Figure 2: show the Tensile Strength values of HDPE with nanoclay at different doses

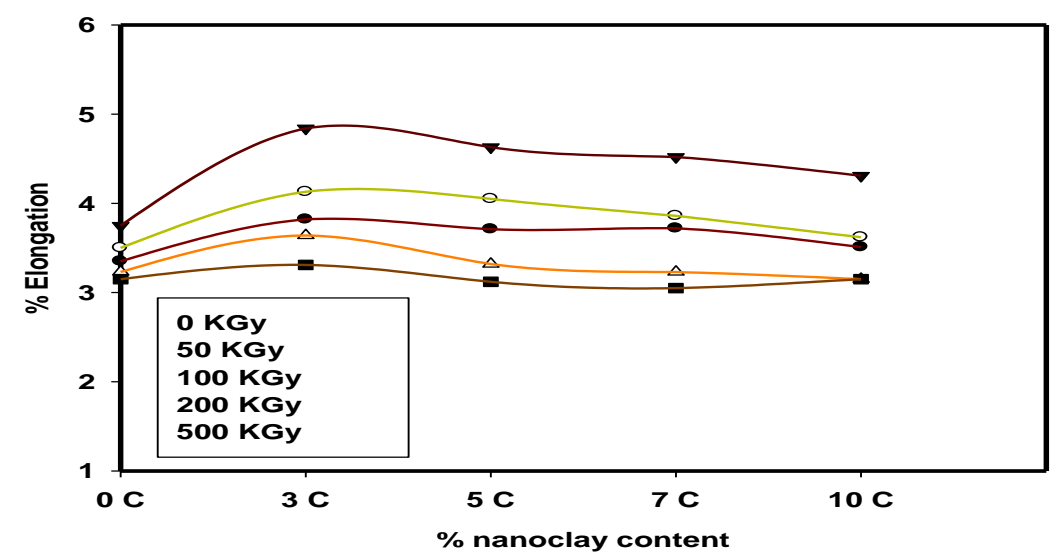

Figure 3: show the Hardness values of HDPE with nanoclay at different doses. 


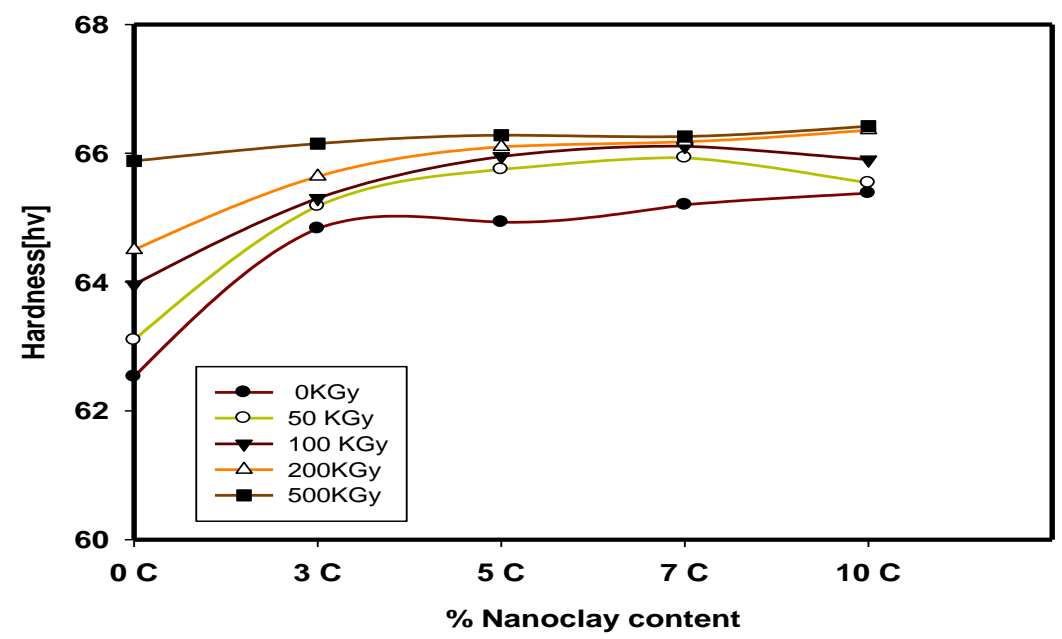

Figure 4: show the Hardness values of HDPE with nanoclay at different doses.

Figure 5 illustrates the variation of tensile strength as a function of irradiation dose for the HDPE/Nanoclay percentage $(0,3,5,7$ and $10 \%)$. It may be observed that tensile strength values for all samples increase with increasing the irradiation dose up to $100 \mathrm{kGy}$, and the optimum addition of nanoclay is $3 \%$ to the high density polyethylene (HDPE). The highest value of tensile strength at $3 \%$ nano-clay and gamma radiation $100 \mathrm{KGy}$ is $25.6 \mathrm{MPa}$.

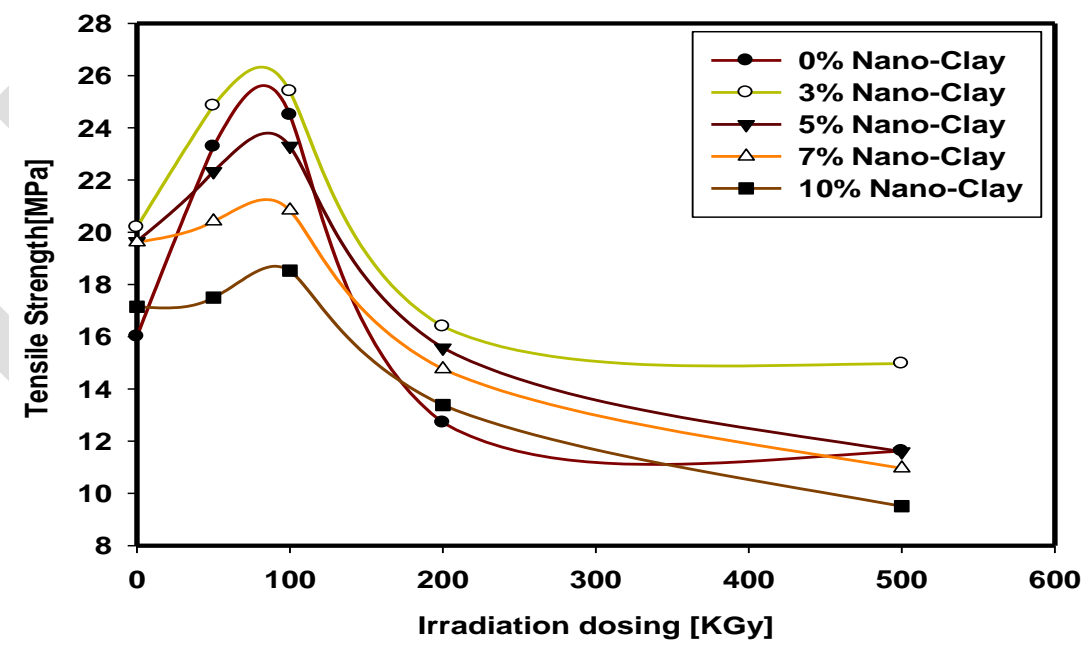

Figure 5: The variation values of tensile strength as a function of irradiation doses.

\section{Conclusion}

The microstructural analysis results indicate that the nano-clay behaves not only as a filler to improve the microstructure, but also as an activator to facilitate the polymer reaction. The results indicate that the nano-clay were exfoliated and dispersed uniformly in the polymer matrix. The results indicate also that the physical and mechanical properties of the modified 
nano-composites enhance with increase the content of nanoclay up to $3 \mathrm{wt} \%$. Gamma irradiation led to a significant improvement in the properties for all composites up to 100 KGy. Also, irradiation of all the composites improved to a considerable extent the physical and mechanical properties that indicates the occurrence of crosslinking.

\section{Reference}

[1]. M. J. Dumont, A. Reyna-Valencia, J. P. Emond, and M.Bousmina, "Barrier properties of polypropylene/organoclay nanocomposites," Journal of Applied Polymer Science, vol. 103, no. 1, pp.618-625, 2007.

[2]. M. Madani and R. Aly "Monitoring of the physical aging of radiation cross-linked conductive rubber blends containing clay nanofiller". Mater Des 31, pp, 44-49, 2016.

[3]. A. P. Mouritz and A. G. Gibson in "Fire Properties of Polymer Composite Materials" (G. M. L. Gladwell Ed.), pp.237-286, 2009.

[4]. C. Lu, Y.-W.Mai, "Influence of aspect ratio on barrier properties of polymer-clay nanocomposite", Phys. Rev. Lett. 95, pp. 303-306, 2015.

[5]. H.R. Dennis, D.L. Hunter, D. Chang and S. Kim, J.L. "Effect of melt processing conditions on the extent of exfoliation in organoclay-based nanocomposite", Polymer 42, pp. 9513-9522, 2017.

[6] A. Zanchet, L .Carli, and M Brandalise " Use of styrene butadiene rubber industrial waste devulcanized by microwave in rubber composites for automotive application". Mater Des 39, pp. 437-443, 2016.

[7] H. Wanga, D. Zhua, and FaLuoa,"Influence of heat treatment on electromagnetic properties of polyimide/carbon black composites", Polym. Adv. Technol, 25, pp.1616-1621, 2014.

[8] W. Zhang, L. Wei, and Y. Fang "In situ intercalative polymerization of poly(methyl methacrylate)/clay nanocomposites by gamma-ray irradiation. Mater Lett 434, pp.51-58, 2011.

[9] H. Youssef, Z.Ali, and K.El-Nemr, "Effect of ionizing radiation on the properties of acrylonitrile butadiene rubber/clay nanocomposites ". J Elastomers Plast 45, PP.407-428, 2012.

[10] S.Kim, C.Dong, and W. Chung "Performance evaluation of a medical radiation shielding sheet with barium as an environment-friendly material", J. Korean Phys. Soc., Vol. 60, pp.165-171, 2012. 
[11] B. Ko"k, M.Yilmaz, and M.Guler "Evaluation of high temperature performance of SBS?

Gilsonite modified binder".Fuel 90: (2016),pp.3093-3099

[12] N. Nita., R.Schaeublin and R. Valiev., "Effects of irradiation on the microstructure and mechanical properties of nanostructured materials". Philos. Mag., Vol. 85, (2005), pp. 723731.

[13] R. Manshaie, S.Khorasani, and M. Abadchi "Effect of electron beam irradiation on the properties of natural rubber (NR)/styrene-butadiene rubber (SBR) blend". Radiat Phys Chem 80, (2011), pp. 100-106. 